\title{
FORMULASI KEBIJAKAN TAX AMNESTY UNDANG-UNDANG NOMOR 11
}

\section{TAHUN 2016}

\section{POLICY FORMULATION OF TAX AMNESTY LAW NUMBER 11 OF 2016}

\author{
Inka Nusamuda Pratama1, Dyah Mutiarin² \\ 1Ilmu Pemerintahan Universitas Muhammadiyah Mataram \\ 2 Ilmu Pemerintahan Universitas Muhammadiyah Yogyakarta \\ E-mail: inkapratama53@gmail.com
}

\begin{abstract}
This article describes the formulation of tax amnesty policy in Law Number 11 Year 2016 which has an impact on the occurrence of polemic. Judging from the approach of the problem stream, political stream and the policy stream. By using qualitative research method, this research shows that in the formulation of tax amnesty policy Law Number 11 Year 2016 seen from the problem stream; the tax amnesty policy provides privileges to taxpayers compared to taxpayers who are taxpayers. Political stream; Metro TV is sometimes very tendentious to censor empirical problems in a dramatic way, thus making Metro TV a group that can lead public opinion, and influence public policy. Policy stream; tax amnesty is currently failing, referring to Article 2 paragraph 2 of the Law amnesty 2016 amid the factors of domestic liquidity, the improvement of the rupiah exchange rate, the decrease of interest rates, the increase of investment, and the tax base. Policy window; President and House of Representatives Commission XI is an Internal actor, Metro TV is an External actor who acts as a policy entrepreneur where the actor encourages more dominant political stream.
\end{abstract}

Keywords: policy formulation, tax amnesty, political stream, policy tream, policy window

\begin{abstract}
ABSTRAK
Artikel ini menjelaskan tentang formulasi kebijakan tax amnesty dalam Undang-undang Nomor 11 Tahun 2016 yang berdampak pada terjadinya polemik.Dilihat dari pendekatan aliran masalah, aliran politik dan aliran kebijakan. Dengan menggunakan metode penelitian kualitatif, penelitian ini menunjukkan bahwa dalam formulasi kebijakan tax amnesty UU Nomor 11 Tahun 2016 dilihat dari aliran masalah; kebijakan tax amnesty tersebut memberikan keistimewaan kepada para pengemplang pajak dibandingkan dengan para Wajib Pajak yang taat membayar pajak. Aliran politik; Metro TV terkadang sangat tendensius mengcover permasalahan empiris dengan cara dramatis, sehingga membuat Metro TV menjadi kelompok yang dapat menggiring opini publik, serta mampu mempengaruhi kebijakan publik.
\end{abstract}

Journal of Governance and Local Politics (JGLP)

ISSN (online): 2684-9992, Vol: 1, Nomor: 1, Mei 2019 
Aliran kebijakan; tax amnesty saat ini mengalami kegagalan, merujuk dari Pasal 2 ayat 2 Undang-Undang tax amnesty 2016 dilihat dari faktor likuiditas domestik, perbaikan nilai tukar rupiah, penurunan suku bunga, peningkatan investasi, dan basis pajak. Jendela kebijakan; Presiden dan DPR RI Komisi XI merupakan aktor Intern, Metro TV adalah aktor Ekstern yang berperan sebagai policy entrepreneur dimana aktor tersebut mendorong aliran politik lebih dominan.

Kata kunci: formulasi kebijakan, tax amnesty, aliran politik, aliran kebijakan, jendela kebijakan

\section{PENDAHULUAN}

Pajak merupakan salah satu sumber penerimaan Negara yang dominan. Lebih dari 70\% sumber pemasukan Anggaran Pendapatan Belanja Negara (APBN) berasal dari sektor pajak (KemenKeu.go.id). Kontribusi pajak dalam Anggaran Pendapatan Negara dari tahun 2015-20171 memberikan bukti bahwa sektor pajak memiliki kontribusi penting dalam memberikan pemasukan pada kas negara. Namun permasalahan yang muncul adanya underground economy atau penggelapan pajak yang sengaja disembunyikan untuk menghindari pembayaran pajak, pelarian modal ke Luar Negeri secara ilegal, dan rekayasa transaksi keuangan yang mengakibatkan kehilangan potensi penerimaan pajak, menambah catatan buruk sektor pajak dalam memberikan kontribusi pemasukan Negara (Devano, 2006). Padahal Pemerintah saat ini sedang berusaha meningkatkan pembangunan Nasional dalam lima tahun kedepan. Sejumlah proyek besar seperti pembangunan tol laut, infrastruktur darat, hingga revitalisasi desa dan pertanian menjadi proyek unggulan. Sehingga Pemerintah berupaya mencari alternatif dari permasalahan yang muncul tersebut.

Tax Amnesty (TA) atau pengampunan pajak yang diatur dalam Undang-undang Nomor 11 Tahun 2016 merupakan kebijakan yang didesain akibat berbagai permasalahan yang muncul sehingga berimbas pada

\footnotetext{
${ }^{1}$ Tahun 2015 APN sebesar Rp. 1.793,6 T, terdiri dari penerimaan pajak Rp.1.380,0 T dan PNBP Rp. 410,3 T. Tahun 2016 APN sebesar Rp. 1.822,5 T, penerimaan pajak Rp. 1.546,7 dan PNBP Rp. 273,8 T. Tahun 2017 APN sebesar Rp.1.750,3 T, terdiri dari penerimaan pajak Rp.1.489,9 T, PNBP sebesar Rp. $250 \mathrm{~T}$
} 
menurunnya penerimaan dari sektor pajak. Tax amnesty yaitu kebijakan yang memberikan penghapusan pajak yang seharusnya terutang, dengan membayar tebusan (uang yang diserahkan kepada kas Negara untuk mendapatakan pengampunan pajak) dalam jumlah tertentu dengan tujuan memberikan pemasukan atau tambahan penerimaan pajak dan kesempatan bagi wajib pajak yang tidak patuh menjadi wajib pajak patuh (Devano \& Rahayu,2006). Kebijakan tax amnesty yang diatur dalam Undang-undang Nomor 11 Tahun 2016 ini dibagi menjadi tiga periode².

Kebijakan tax amnesty menjadi kebutuhan yang mutlak bagi Indonesia untuk membiayai pembangunan dan pengentasan kemiskinan. Tax amnesty memberikaan implikasi positif terhadap masyarakat, dana hasil pemanfaatan tax amnesty yang sangat besar ini diharapkan menambah modal Pemerintah untuk mempercepat program pembangunan sehingga dapat mengurangi pengangguran dan kemiskinan (Darussalam, 2015).

Namun kebijakan tax amnesty (pengampunan pajak) justru berimplikasi terjadinya polemik. Disatu sisi kebijakantax amnesty sebagai upaya mencapai target penerimaan Negara (APBN), serta meningkatkan tax ratio sebesar 14\% (empat belas persen) melalui intensifikasi dan ekstensifikasi. Di sisi lain kelemahan dari kebijakan ini yaitu dalam waktu jangka panjang dapat berakibat buruk, berupa menurunnya kepatuhan sukarela (voluntary compliance) dari wajib pajak patuh. Ketika melihat orientasi tujuan dari kebijakan tax amnesty, maka telah mengabaikan keadilan dari sudut pandang pembayar pajak yang selama ini telah patuh (konsisten) dalam membayar kewajiban pajaknya. Terlebih lagi ini bukan kali pertama Tax Amnesty (TA) diterapkan oleh Pemerintah, namun sudah tiga kali dilakukan dan hasilnya kurang maksimal ${ }^{3}$ (Ragimun, 2016; Setiadi,

\footnotetext{
${ }^{2}$ Periode pertama dimulai dari 28 Juni-31 September 2016, periode ke-dua 1 Oktober-31 Desember 2016 dan periode ke-tiga 1 Januari-Maret 2017

${ }^{3}$ Pengampunan pajak tahun 1964 , kemudian pengampunan pajak tahun 1984, dan Sunset Policy tahun 2008
} 
2016; Darmayasa, 2016; Kumalasari, 2017; Fatmala, 2017; Firdaus, 2016; Rustanti, 2017).

\section{METODE PENELITIAN}

Artikel ini berangkat dari hasil penelitian yang menggunakan pendekatan penelitian kualitatif. Pendekatan penelitian kualitatif bermaksud untuk memahami tentang apa yang dialami oleh subjek penelitian dengan cara deskripsi dalam bentuk kata-kata dan bahasa dengan memanfaatkan berbagai metode alamiah (Moleong, 2007). Sasaran dari penelitian ini adalah Direktorat Jenderal Pajak Kementerian Keuangan RI, Institute for Development of Economics and Finance (INDEF), serta Metro TV.

Pertimbangan peneliti melakukan penelitian pada Direktorat Jenderal Pajak (DJP) Kementerian Keuangan Republik Indonesia, sebagai entitas yang mendapatkan mandat untuk mengelola administrasi perpajakan secara Nasional (tax administrator).Kemudian Institute for Development of Economics and Finance (INDEF) sebagai Non Governmental Organization (NGO). Serta media dalam hal ini Metro TV memiliki peran yang sangat krusial dalam mensukseskan kebijakan Pemerintah. .Teknik pengumpulan data yang digunakan yaitu dokumentasi dan wawancara. Studi dokumentasi dilakukan mengenairasio penyampaian Surat Pemberitahuan Tahunan (SPT) Wajib Pajak Orang Pribadi, Tax Ratiodi Indonesia, dan latar belakang pihak kontra dalam melihat kebijakantax amnesty. Wawancara dilakukan pada Direktorat Jenderal Pajak bidang Direktorat Penyuluhan, Pelayanan dan Hubungan Masyarakat (P2 Humas), peneliti Institute for Development of Economics and Finance (INDEF) dan pihak Metro TV.

\section{HASIL DAN DISKUSI}

Dalam menguraikan formulasi kebijakantax amnesty yang tertuang dalam Undang-undang Nomor 11 Tahun 2016, teori yang digunakan yaitus tream window model (Model Aliran Jendela) oleh Kingdon. Kebijakan yaitu 
produk dari penggabungan (kovergensi) dari tiga aliran proses khas yang mengalir melalui sistem politik. Menurut Kingdon (dalam Hamdi, 2014:82) ketiga aliran tersebut yaitu aliran masalah (problemstream), aliran kebijakan (policy stream), dan aliran politik (political stream). Model ini berangkat dari pengandaian bahwa sebuah kebijakan yang dapat dilaksanakan haruslah dicapai setelah terbukanya "jendela" yang didorong oleh ketiga aliran besar tersebut.

Ketiga arus tersebut kemudian akan dipertemukan dan disatukan oleh Policy Entrepreneur (PE) yang berfungsi untuk membuka jendela kebijakan (policy window). Artinya bahwa kebijakan publik akan terbentuk jikaPolicy Entrepreneur (PE) kebijakan mendorong serta mempertemukan ketiga arus tersebut. Adapun PE (Policy Entrepreneur) yaitu aktor baik yang berada dari dalam ataupun luar Pemerintahan yang dengan rela menginvestasikan waktu, energi, reputasi, uang, dan pegawai untuk mencapai tujuan dan nilai yang diinginkan (Jean, 2012; Jenkind dan Les Alm, 2003).

\section{Aliran Masalah (Problem Stream)}

Aliran Masalah (Problem Stream) merupakan suatu keadaan atau peristiwa yang terjadi ditengah-tengah masyarakat. Kingdon (dalam Hamdi, 2014) menjelaskan bahwa jika suatu kondisi ingin dijadikan suatu masalah, maka orang-orang harus memiliki pemikiran bahwa suatu tindakan seharusnya dilakukan untuk mengubahnya. Melalui aliran masalah (problem stream) yang dilihat dari beberapa aspek yaitu: penyebab terjadinya masalah perpajakan, polemik kebijakan tax amnesty, pihak yang berkepentingan dalam agenda kebijakantax amnesty.

Rendahnya kepatuhan wajib pajak untuk melaporkan Surat Pemberitahunan Tahunan (SPT) menjadi salah satu hal yang berkontribusi terhadap rendahnya penerimaan pajak. Jumlah pekerja sebesar 114,819 juta jiwa (pada tahun 2015), baru 27,571 juta jiwa yang telah terdaftar sebagai wajib pajak orang pribadi, dengan kata lain hanya 24,01\% dari potensi jumlah pekerja yang telah mendaftarkan diri sehingga masih terdapat 
potensi sekitar 87 juta Wajib Pajak yang belum terdaftar dalam sistem administasi perpajakan (Wawancara pada DJP bidang DPP dan HuMas, 02 September 2017).

Tabel 1.

Rasio Penyampaian Surat Pemberitahuan Tahunan Wajib Pajak Orang Pribadi

\begin{tabular}{|c|c|c|c|c|c|}
\hline Uraian/Tahun & $\mathbf{2 0 1 1}$ & $\mathbf{2 0 1 2}$ & $\mathbf{2 0 1 3}$ & $\mathbf{2 0 1 4}$ & $\mathbf{2 0 1 5}$ \\
\hline $\begin{array}{c}\text { WP OP } \\
\text { Terdaftar } \\
\text { (juta) }\end{array}$ & 19,881 & 20,131 & 22,231 & 25,127 & 27,571 \\
\hline $\begin{array}{c}\text { Pekerja } \\
\text { (juta) }\end{array}$ & 107,416 & 112,504 & 112,761 & 114,628 & 114,819 \\
\hline $\begin{array}{c}\text { Rasio WP OP } \\
\text { Terdaftar } \\
\text { (\%) }\end{array}$ & $18,51 \%$ & $17,89 \%$ & $19,72 \%$ & $21,92 \%$ & $24,01 \%$ \\
\hline
\end{tabular}

Sumber: Data DJP Tahun 2016

Dalam satu dekade terakhir ini, penerimaan dari sektor pajak di Indonesia belum optimal yang ditandai dengan tax ratio (rasio pajak) yang masih tergolong rendah.Tax ratio Indonesia dari tahun 2006 sampai pada tahun 2015 mengalami instabilitas, namun pada tahun 2008 ada kenaikan positif dibandingkan tahun sebelumnya maupun sesudahnya, dikarenakan pada tahun 2008 adanya sunset policy 4

\footnotetext{
${ }^{4}$ Kebijakan pemberian fasilitas perpajakan, yang berlaku hanya pada tahun 2008 , dalam bentuk penghapusan sanksi administrasi perpajakan berupa bunga yang diatur dalam Pasal 37A UndangUndang Ketentuan Umum dan Tata Cara Perpajakan (Undang-Undang Nomor 28 Tahun 2007).
} 
Grafik 1.

Tax Ratio Indonesia

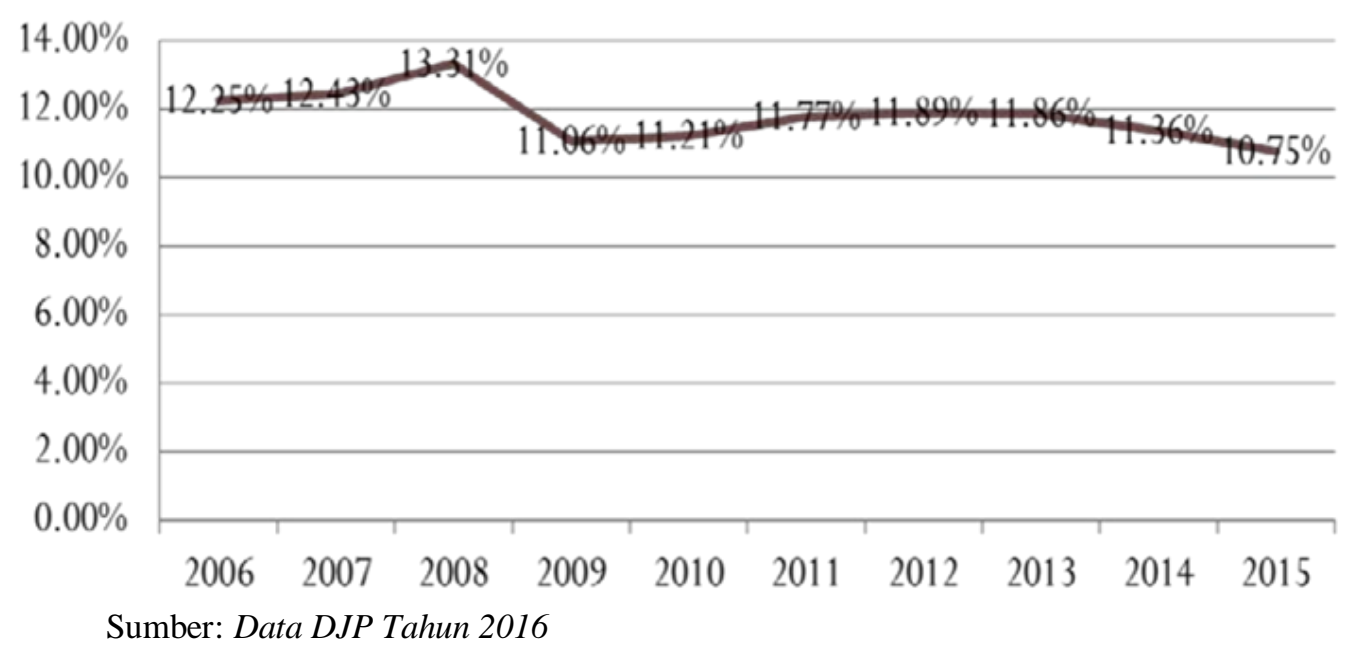

Tabel 2.

Tax Ratio Negara Asean (Dalam \%)

\begin{tabular}{|c|c|c|c|c|c|}
\hline Negara & $\mathbf{2 0 0 8}$ & $\mathbf{2 0 0 9}$ & $\mathbf{2 0 1 0}$ & $\mathbf{2 0 1 1}$ & $\mathbf{2 0 1 2}$ \\
\hline Malaysia & 14.66 & 14.94 & 13.33 & 14.79 & 15.61 \\
\hline Filipina & 13.59 & 12.23 & 12.15 & 12.38 & 12.89 \\
\hline Singapura & 13.85 & 13.07 & 12.97 & 13.30 & 13.85 \\
\hline Thailand & 15.38 & 14.20 & 14.94 & 16.37 & 15.45 \\
\hline
\end{tabular}

Sumber: Data DJP Tahun 2016

Berdasarkan data Direktorat Jenderal Pajak, Tax ratio di Indonesia pada tahun 2012 berada pada kisaran angka 11.9\%, sedangkan pada Negaranegara tetangga seperti Malaysia pada kisaran angka 15.61\%, kemudian Singapura dikisaran angka 13.85\%, selanjutnya Philipina 12.89\%, dan terakhir Thailand dikisaran angka $15.45 \%$. Artinya bahwa tax ratio Indonesia sangat rendah apabila dikomparasikan dengan Negara-negara kawasan ASEAN lainnya.

Kingdon mengatakan dalam teorinya, bahwa sebuah permasalahan tertentu akan dianggap penting sebagai masalah publik dan perlu diselesaikan jika terdapat beberapa hal seperti indikator, focusing event, dan feedback.Secara empiriskebijakan tax amnestyyang diatur dalam Undang- 
undang Nomor 11 Tahun 2016, diwujudkan melalui indikator rendahnya penerimaan dari sektor pajak, yang diakibatkan oleh meningkatnya jumlah pengemplang pajak, sampai pada Wajib Pajak yang membawa keluar Negeri hartanya pada Negara yang memberi sanksi pajak lebih rendah (tax haven). Reformasi mental yang didengung-dengungkan oleh Presiden dan Nawacitanya merupakan focusing event, dimana peristiwa ini mampu mengarahkan perhatian publik, dan publik menganggap bahwa kebijakan pengampunan pajak (tax amnesty) merupakan kebutuhan yang mendesak (feedback).

\section{Gambar 1.}

\section{Alur Aliran Masalah (Problem Stream) Dalam Kebijakan Tax Amnesty} UU No.11 Thn. 2016

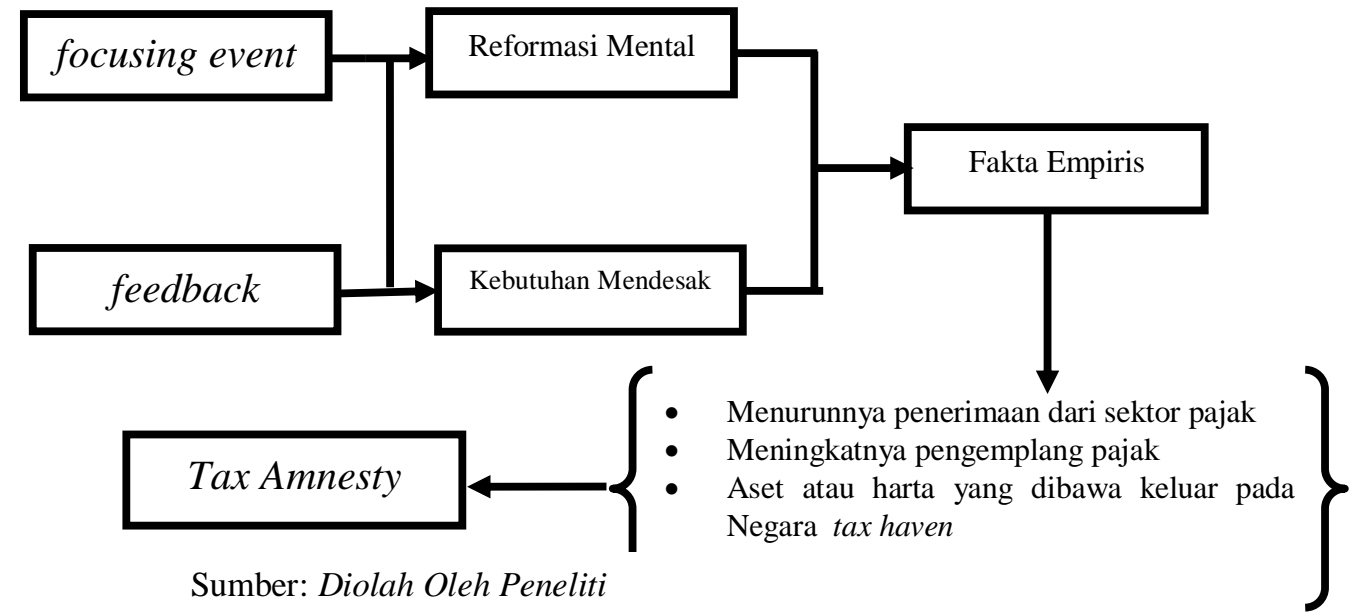

Peneliti telah memetakkan aktor yang terlibat dalam formulasi kebijakan tax amnesty (TA) dalam Undang-undang Nomor 11 Tahun 2016 sebagai berikut:

Tabel 3.

\section{Road Map Aktor Dalam Formulasi Kebijakan Tax Amnesty} Dalam UU No. 11 Tahun 2016

\begin{tabular}{|c|c|}
\hline Kategori Stakeholder & Aktor \\
\hline Stakeholder Kunci & Presiden (Eksekutif) dan DPR RI (Legislatif) \\
\hline Stakeholder Primer & KemenKeu RI dan Direktorat Jenderal Pajak RI \\
\hline Stakeholder Sekunder & Akademisi, Pengusaha Indonesia, Media \\
\hline
\end{tabular}


Stakeholder kunci merupakan aktor yang memiliki kewenangan legal membuat serta mendesain kebijakan. Sementara stakeholder primer merupakan kelompok yang memiliki kaitan langung dengan kebijakan yang sedang dibahas. Sedangkan stakeholder sekunder merupakan aktor yang tidak memiliki kepentingan langsung, namun memiliki kepedulian terhadap pokok permasalahan kebijakan.

Kebijakan tax amnesty yang didesain oleh Pemerintah, diharapkan mampu meningkatkan penerimaan pajak, mengeliminasi penghindaran pajak, memperluas basis data perpajakan dan juga untuk memperbaiki kepatuhan pajak, artinya bahwa kebijkan ini dianggap sebagai formulasi kebijakan yang tepat dari rentetan masalah yang dihadapi dalam sektor perpajakan di Indonesia (Wawancara pada DJP bidang DPP dan HuMas, 02 September 2017).

Namun kebijakan tax amnesty diwarnai terjadinya polemik antara Pemerintah dengan pihak yang kontra dalam hal ini Forum Indonesia untuk Transparansi Anggaran (FITRA), PP Muhammadiyah dan Civil Society lainnya. Pihak kontra menilai berdasarkan data dari Institute for Development of Economics and Finance (INDEF), tax amnesty berdampak pada anomali yang hanya menambah penderitaan rakyat, pembentukan kebijakan tax amnesty yang cacat secara konstitusional, padahal pemungutan pajak dalam proses Anggaran Pendapatan Belanja Negara (APBN) sudah ada sistem hukumnya yang bersifat memaksa bukan mengampuni, sebagaimana yang telah diatur dalam UUD 1945 pasal 23 A. Artinya bahwa tax amnesty memberikan keistimewaan (privilege) kepada para pengemplang pajak (tax evaders) dibandingkan dengan para Wajib Pajak yang taat membayar pajak (honest taxpayers). Undang-undang tax amnesty ini merupakan upaya mendelegitimasi upaya pemberantasan korupsi, dalam prakteknya tidak ada verifikasi asal harta, apakah dari korupsi, ilegal logging, narkoba dan kejahatan lainnya. 
Gambar 2.

Alur Polemik Kebijakan Tax Amnesty dalam Undang-Undang Nomor 11 Tahun 2016

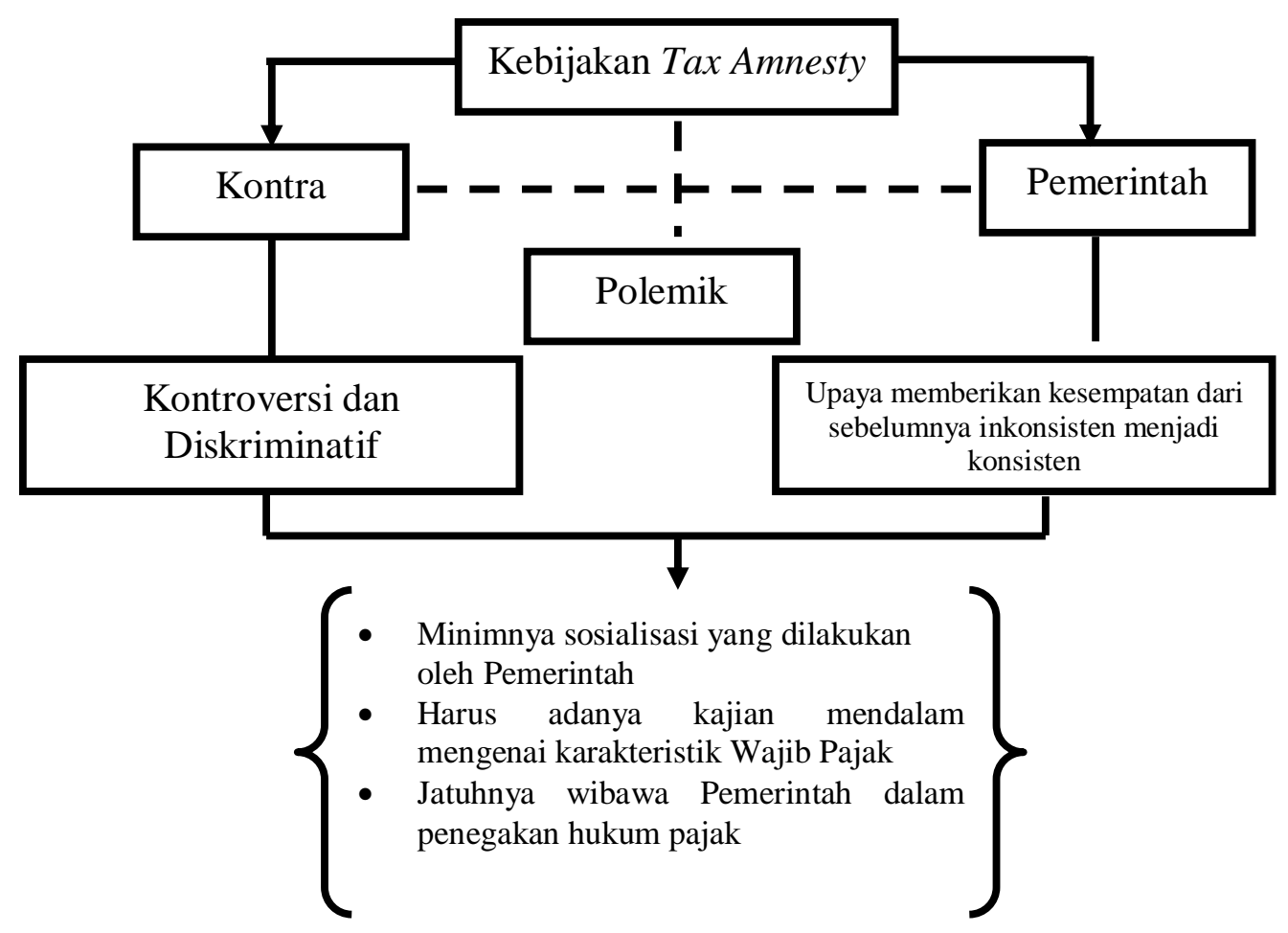

Sumber: Diolah oleh Peneliti

Dalam formulasi kebijakan, dibutuhkan perencanaan yang sangat matang, yang didesain dengan mempertimbangkan aspek-aspek terkait masalah yang ada, agar perumusan atau formulasi sebuah kebijakan berjalan secara terintegrasi dan tersistematis.Tidak ada pedoman yang dapat dijadikan dasar dalam merancang kebijakan pajak.Kebijakan tax amnesty saat ini hanya bertumpu pada target penerimaan yang pada akhirnya kebijakan yang dibuat seringkali tidak terencana, cenderung sporadis pada akhirnya bersifat "trial and error". (Wawancara dengan Bhima Yudhistira peneliti Institute for Development of Economics and Finance(INDEF) 04 September 2017). 


\section{Aliran Politik (Political Stream)}

Aliran Politik (political stream) terkait dengan situasi politik yang mempengaruhi perhatian publik untuk mendorong atau bahkan menghambat kebijakan publik, terkait dengan permasalahan perpajakan yang saat ini sedang dialami. Kondisi politik nasional (national mood) pada saat itu dipengaruhi oleh semangat revolusi mental sebagai slogan Pemerintah, serta Nawacita sebagai visi dan misi yang tertanam dalam sembilan agenda pokok untuk melanjutkan semangat perjuangan dan citacita Soekarno yang dikenal dengan istilah Trisakti, yakni berdaulat secara politik, mandiri dalam ekonomi, dan berkepribadian dalam kebudayaan.

Setelah pasangan Jokowi-Kalla terpilih menjadi Presiden dan Wakil Presiden dalam periode 2014-2019, nuansa perpolitikan Nasional semakin klimaks. Menurut Arifin (2001), setiap konstelasi politik dari setiap aktor yang berkepentingan akan melakukan komunikasi politik dengan citra dan opini publik. Publik mendengung-dengungkan serta menuntut realisasi janji politik. Artinya bahwa kebijakan tax amnesty yang diatur dalam UndangUndang Nomor 11 Tahun 2011 merupakan wujud dari citra dan opini publik.

Kebijkan tax amnesty telah membentuk opini publik. Berbagai spekulasipun muncul, bahwa Pemerintah dinilai telahlemah dan sudah putus asa dalam menarik iuran pajak dari para Wajib Pajak, dengan mengeluarkan kebijakan yang "memohon" kepada masyarakat untuk membayar pajak. Pemerintah juga memberikan keistiwekan para pengusaha dalam penegakan hukum pajak, selain hal tersebut unsur kepentingan juga menjadi bumbu dalam kebijakan tax amnesty.

Di tengah-tengah polemik kebijakan tax amnesty, di sisi lainnya media dalam hal ini Metro TV cenderung bersikap pro, artinya ikut menuntut agar kebijakan tax amnesty segera direalisasikan oleh Pemerintah, sehingga kondisi ini semakin mendorong permasalahan perpajakan menjadi isu yang sangat strategis. Kebijakantax amnesty ini memiliki dampak yang cukup besar dalam sektor pajak, oleh karena itu harus didukung (Wawancara 
dengan pihak Metro TV 05 September 2017). Metro TV sebagai media elektronik terkadang sangat tendensius mengcover permasalahan empiris dengan cara dramatis, sehingga membuat Metro TV menjadi kelompok yang mampu mempengaruhi kebijakan publik (aktor politik). Pemilik sekaligus ketua umum partai Nasdem Surya Paloh, yang termasuk salah satu yang mendukung Pemerintahan saat ini. Maka tidak heran, sisi positif dipertontonkan dan diangkat pada publik.

\section{Gambar 3.}

Aliran Politik (Political Stream) Kebijakan Tax Amnesty dalam Undang-undang Nomor 11 Tahun 2016

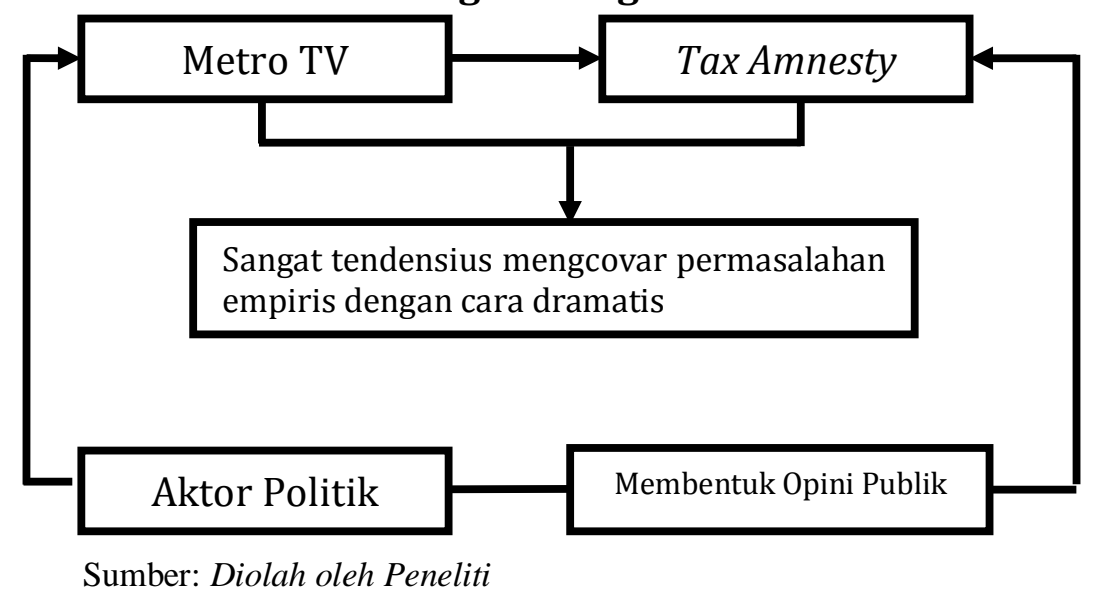

Kebijakan Pemerintah tidak terlepas dari adanya unsur politik yang mendasarinya,dibandingkan dengan menjalankan pekerjaan hukum yang seharusnya ditegakkan (Mahfud MD dalam Laili Bariroh 2012). Adanya kaitan antara kebijakan Pemerintah dengan politik, maka pembentukan Undang-undang pengampunan pajak atau tax amnesty dalam Undang-undang Nomor 11 Tahun 2016 tidak lepas dari kepentingan politik,hal ini memungkinkan adanya penyaluran kepentingan bagi sebagian atau seluruh elit politik yang bekerja dalam hal pembentukan peraturan perundangundangan. Walau dasar diberlakukannya Undang-undang tax amnesty tersebut telah jelas tertuang dalam konsiderans ${ }^{5}$.

\footnotetext{
${ }^{5}$ Pertama, pembangunan nasional NKRI yang bertujuan untuk memakmurkan seluruh rakyat Indonesia yang merata dan berkeadilan, memerlukan pendanaan besar yang bersumber utama dari penerimaan pajak. Kedua, untuk memenuhi kebutuhan penerimaan pajak, diperlukan
} 


\section{Aliran Kebijakan (Policy Stream)}

Tujuan utama dari adanya tax amnesty yaitu repatriasi dan harta tebusan. Repatriasi dari Rp. 1.000 Triliun target, hanya Rp. 147 Triliun yang terealisasi, ini membuktikan bahwa dari sisi repatriasi jauh dari harapan, serta harta deklarasi luar Negeri dari target potensi penerimaan Pemerintah Rp. 11.000 Triliun yang terealisasi hanya Rp. 1.179 Triliun. Kebijakan tax amnesty yang telah dilakukan oleh Pemerintah saat ini bisa dikatakan gagal, mengacu pada pasal 2 ayat 2 dalam Undang-Undang Nomor 11 Tahun 2016.Dilihat dari likuiditas domestik, perbaikan nilai tukar rupiah, penurunan suku bunga, peningkatan investasi, dan basis pajak yang tidaksignifikan.(Wawancara dengan peneliti Institute for Development of Economics and Finance (INDEF) 04 September 2017).

Dari sisi likuiditas domestik repatriasi tidak memberikan pengaruh yang signifikan terhadap pertumbuhan ekonomi. Kemudian perbaikan nilai tukar rupiah dari dana repatriasi yang diharapkan memperkuat struktur rupiah, tidak mampu berbicara banyak. Berharap ketika Warga Negara Indonesia yang berada diluar Negeri ingin memasukkan uangnya ke Indonesia, otomatis harus menukarkan mata uang Luar Negeri dengan rupiah. Seharusnya ini berdampak pada nilai tukar rupiah yang semakin baik, namun ini tidak terjadi.

Penurunan suku bunga tidak dapat turun. Pada tahun 2016 beberapa kali Bank Indonesia menurunkan suku bunga acuan, namun langkah tersebut dapat dikatakan gagal.Suku bunga kredit penurunannya sangat lambat. Adanya tax amnesty dengan repatriasi masuk ke Indonesia melaui pihak ketiga seharusnya transmisi penurunan suku bunga acuan Bank Indonesia kepada kredit perbankan lebih cepat.

kesadaran dan kepatuhan masyarakat. Tiga, Kesadaran dan kepatuhan masyarakat dalam melaksanakan kewajiban perpajakannya masih perlu ditingkatkan. Empat, meningkatkan penerimaan Negara dan pertumbuhan perekonomian 
Peningkatan investasi dari dana repatriasi sebesar 70\% berputar pada sektor keuangan (sektor financial). Diharapkan dapat menetes pada usaha paling bawah, karena sesuai amanat Undang-undang tax amnesty salah satunya dapat menggerakkan perekonomian nasional, namun apabila hanya masuk pada deposito, surat berharga, obligasi, dan saham, bagaimana mungkin dapat menetes pada pelaku Usaha Mikro Kecil dan Menengah (UMKM). Otomatis ini akan berimplikasi pada penyerapan tenaga kerja yang tidak berjalan dengan baik.

Kemudian basis pajak merupakan salah satu tujuan dari kebijakan tax amnesty,yaitu untuk memperluas basis pajak yang sangat kecil, namun faktanya yang terjadi basis pajak yang baru apabila ditotal dari Wajib Pajak yang ikut dalam tax amnestysaat ini sekitar 560.000 orang, yang artinya 1,89\% dari total Wajib Pajak yang ada sekitar 22 juta orang, ini membuktikan bahwa tax amnesty gagal.

\section{Gambar 4.}

\section{Kegagalan Tax Amnesty Diukur Dari Lima Indikator Dalam Pasal 2 ayat} 2 dalam UU No. 11 Thn. 2016

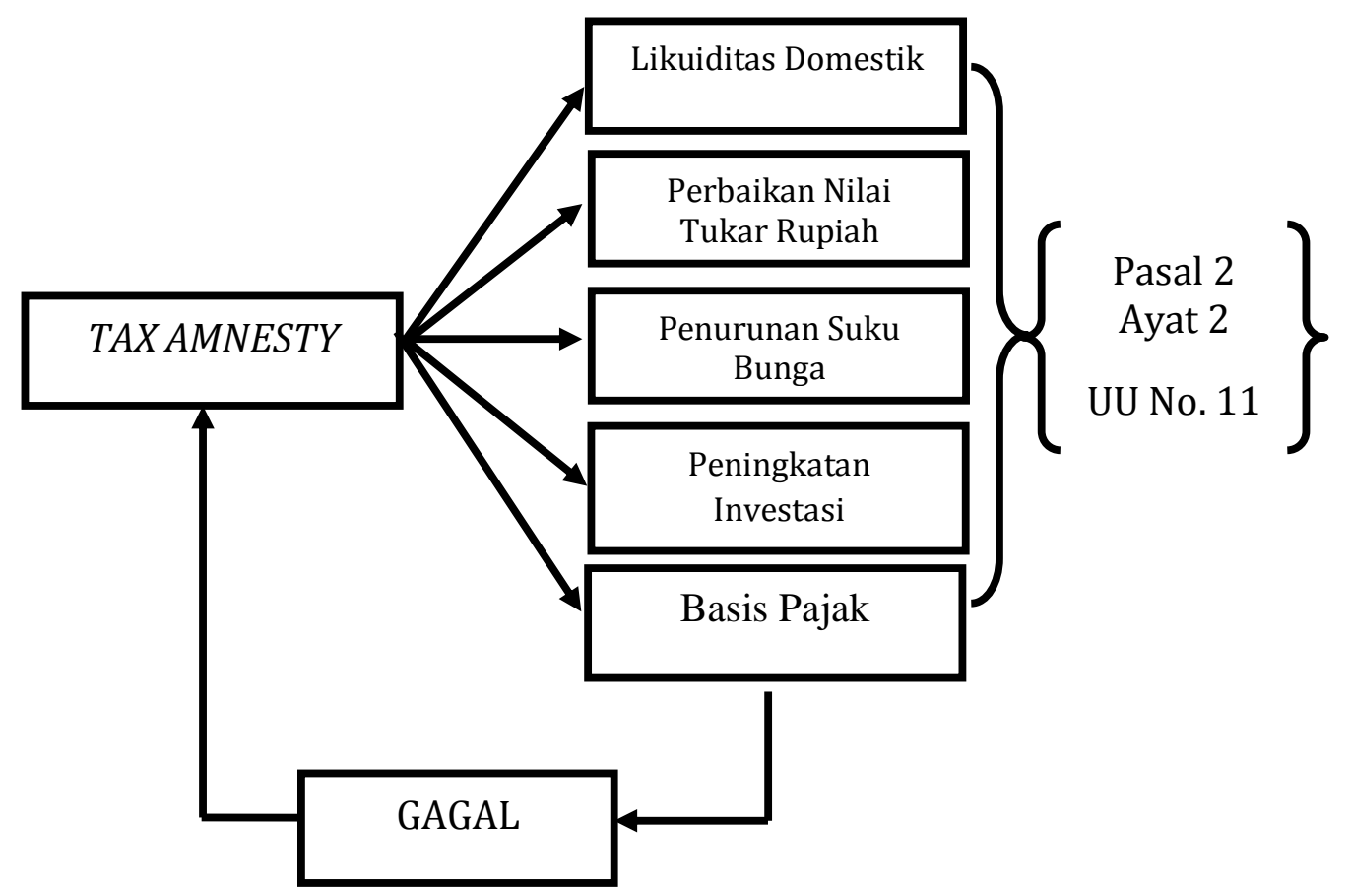

Sumber: Diolah oleh Peneliti 
Dalam konsep teoritik Kingdon, aliran kebijakan (policy stream) yaitu proses bertarungnya ide atau gagasan sebagai proposal kebijakan yang diibaratkan dengan memasak sup (policy primeval soup).Sebelum melakukan kebijakan tax amnesty, perbaikan pada data base kependudukan sangat penting, artinya bahwa ketika seseorang ingin membuka usaha dalam mendapatkan perizinan, maka secara otomatis wajib pajak dapat terdeteksi dengan munculnya Nomor Pokok Wajib Pajak (NPWP). Ketika data base kependudukan berjalan baik diimbangi dengan data base pajak, maka akan memperluas cakupan Wajib Pajak. (Wawancara dengan pihak Institute for Development of Economics and Finance (INDEF) 04 September 2017). Artinya bahwa sebelum kebijakan tax amnesty diterapkan, Pemerintah terlebih dahulu harus melakukan perbaikan data base kependudukan yang telah tersusun rapi, serta perizinan usaha telah terintegrasi dan bisa terkoneksi dengan Nomor Pokok Wajib Pajak (NPWP).

\section{Jendela Kebijakan (Policy Window)}

Policy Window yaitu kondisi yang memungkinkan bersatunya tiga arus menjadi sebuah kebijakan publik, dimana untuk mencapai kondisi ini diperlukan aktor yang dinamakan policy entrepreneur (Certien, 2012). Adapun policy entrepreneur yaitu individu atau organisai baik dari dalam Pemerintahan atau dari luar Pemerintahan, yang mengidentifikasi, serta membentuk, dan mendorong perhatian aktor kebijakan lain, terhadap masalah dan atau solusi yang sedang dikaji untuk mendapatkan keuntungan.

Berdasarkan kategori policy entrepreneur (PE) dan pengamatan secara empiris, peneliti mencoba untuk menyimpulkan bahwa aktor yang berperan sebagai policy entrepreneur (PE) dalam formulasi kebijakan tax amnesty (pengampunan pajak) yaitu Presiden sebagai lembaga eksekutif serta Dewan Perwakilan Rakyat Republik Indonesia (DPR RI) sebagai lembaga legislatif dan media. Presiden dan Dewan Perwakilan Rakyat Republik Indonesia (DPR RI) merupakan aktor intern. Sedangkan media merupakan aktor ekstern.Keduanya mengidentifikasi serta membentuk, dan 
mendorong perhatian publik untuk memperhatikan permasalahan perpajakan yang ada di Indonesia. Secara konseptual, dapat peneliti gambarkan sebagai berikut:

\section{Gambar 5.}

Aktor Policy Entrepreneur

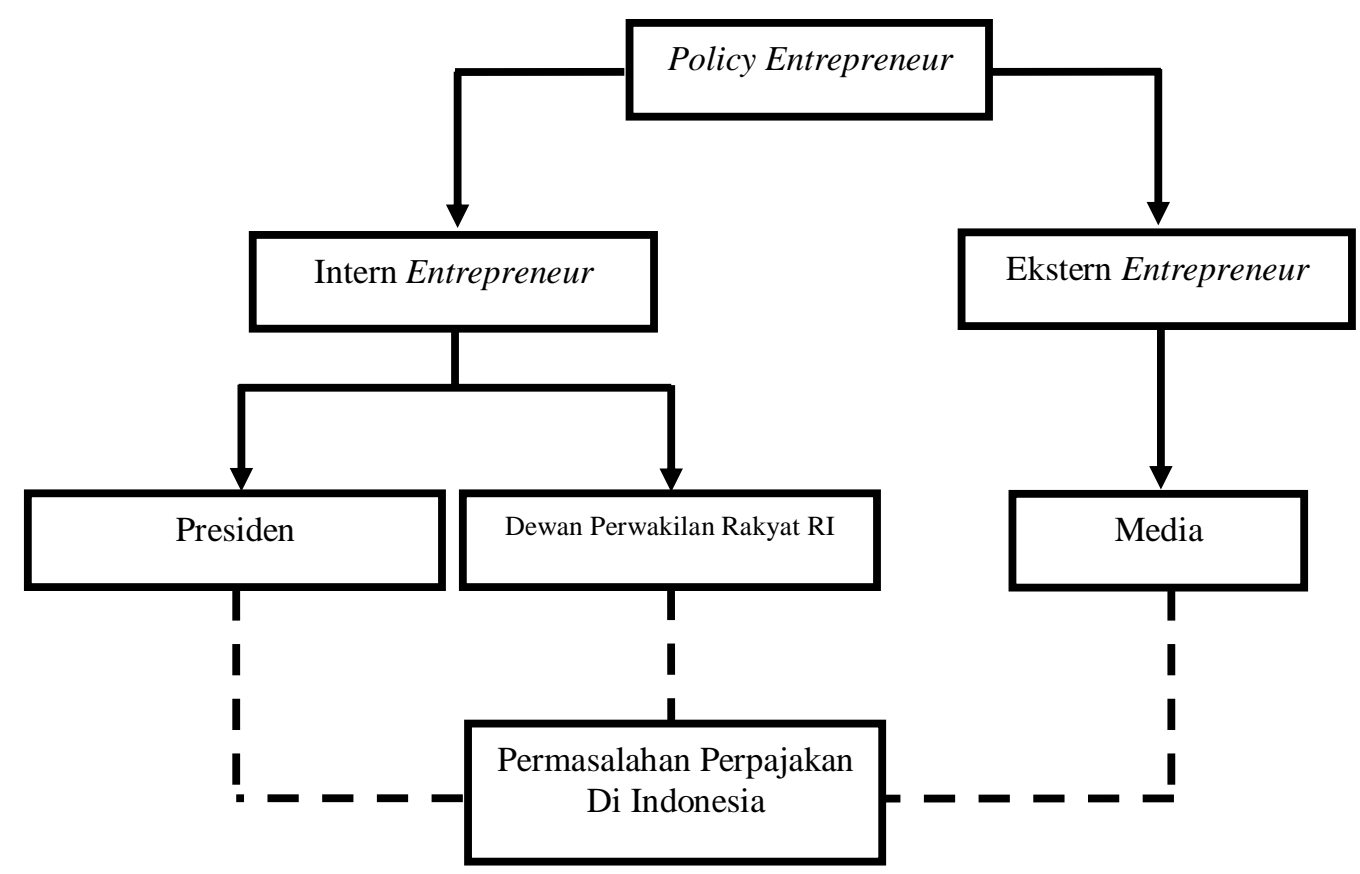

Sumber: Diolah oleh Peneliti

Berdasarkan penelitian ini, peneliti menemukan fakta bahwa terdapat hubungan yang tidak independen dan kekuatan arus yang tidak simultan antara Aliran masalah (Problem Stream), Aliran politik (Politics Stream), dan Aliran Kebijakan (Policy Stream). Adapun secara konseptual, dapat peneliti gambar sebagai berikut: 
Gambar 6.

Pengembangan Model Formulasi Kebijakan Kingdon Berdasarkan Hasil Penelitian Formulasi Kebijakan Tax Amnesty (Pengampunan Pajak) Dalam UU No. 11 Tahun 2016

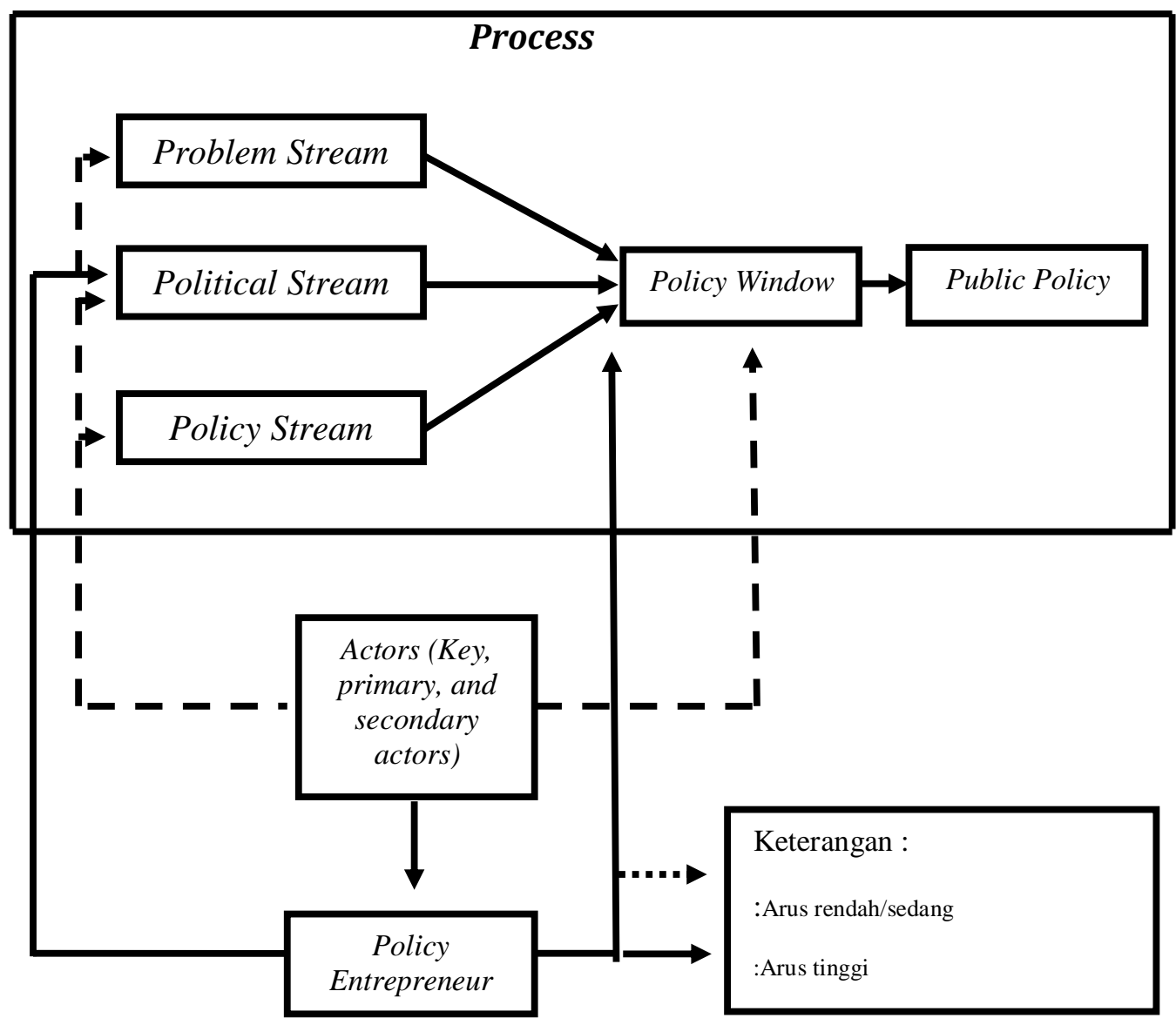

Sumber:Diolah oleh Peneliti

Gambar tersebut menjelaskan bahwa Political Stream (Aliran Politik) memiliki kekuatan yang lebih dominan, dimana arus ini mampu memberikan dorongan pada Problem Stream (Aliran Masalah) dan Policy Stream (Aliran Kebijakan). Oleh karena itu, policy entrepreneur (aktor kebijakan) akan menggunakan aliran politik lebih dominan dibandingkan dengan aliran lain untuk membuka policy window (jendela kebijakan). Kekuatan masing-masing aliran inilah yang tidak dijelaskan dengan lebih rinci oleh Kingdon.Berdasarkan hal ini, artinya tidak terdapat hubungan yang murni atau independen pada masing-masing aliran. 


\section{Kesimpulan}

Formulasi kebijakan tax amnesty dalam Undang-undang Nomor 11 Tahun 2016 yang berdampak pada terjadinya polemik. Dilihat dari pendekatan aliran masalah (problem stream); kebijakan tax amnesty tersebut memberikan keistimewaan (privilege) kepada para pengemplang pajak (tax evaders) dibandingkan dengan para wajib pajak yang taat membayar pajak (honest taxpayers). Aliran politik (political stream); Metro TV terkadang sangat tendensius mengcovar permasalahan empiris dengan cara dramatis, sehingga membuat Metro TV menjadi kelompok yang dapat menggiring opini publik, serta mempu mempengaruhi kebijakan publik. Aliran kebijakan (policy stream); tax amnesty saat ini mengalami kegagalan, merujuk dari pasal Pasal 2 ayat 2 Undang-Undang tax amnesty 2016 dilihat dari faktor likuiditas domestik, perbaikan nilai tukar rupiah, penurunan suku bunga, peningkatan investasi, dan basis pajak.Pemerintah terlebih dulu harus memperbaiki data base kependudukan yang dapat terintegrasi langsung dengan Nomor Pokok Wajib Pajak (NPWP). Jendela kebijakan; Presiden dan DPR RI Komisi XI merupakan aktor Intern, Metro TV adalah aktor Ekstern yang berperan sebagai policyentrepreneur dimana aktor tersebut mendorong aliran politik lebih dominan. Penelitian ini merekonstruksi teori Kingdon dengan memperjelas bahwa masing-masing aliran tidak berjalan simultan dan tidak murni atau independen karena aliran politik (political stream) lebih kuat dibandingkan dengan aliran masalah (problem stream) serta aliran kebijakan (policy stream).

\section{REFRENSI}

Arifin , Ali. 2001. Membaca saham. Edisi Pertama. Yogyakarta: Andi Offset

Bariroh, Laili. 2012. Politik Hukum Nasional dan Hegemoni Globalisasi Ekonomi. Jurnal Review Politik. Vol 2, Nomor 2 Hal. 199. IAIN Sunan Ampel Surabaya 
Certien, J. 2012. Policy Entepreneur: A Case Study of The 2002 G8 Summit in Kananaskis, Alberta. Canada: University of Saskatchewan

Darmayasa, dkk. 2016. Deconstruction of equitable tax amnesty. International Journal of Applied Business and Economic Research (IJABER), 14(11), 8167-8179

Darussalam. (2015). Memanfaatkan Pengampuan Pajak: Pahami dan Memanfaatkan Reinventing Policy

Devano, S., \& Rahayu, S. K. (2006). Perpajakan: Konsep. Teori dan Isu, Prenada Media Grup, Jakarta.

Fatmala, N. D. (2017). PERSEPSI WAJIB PAJAK PADA PROGRAM TAX AMNESTY UNTUK MENINGKATKAN PENERIMAAN PAJAK. Jurnal Ilmu dan Riset Akuntansi, 6(8).

Firdaus, A. (2016, July). Re-Aktualisasi Tax Amnesty: Suatu Kajian Untuk Meningkatkan Kepatuhan Pajak. In Prosiding Industrial Research Workshop and National Seminar (Vol. 7, pp. 110-119).

Hamdi, Muchlis, 2014. Kebijakan Publik. Proses Analisis, dan Partisipasi.Bogor: Ghalia Indonesia.

HARYADI, D. (2017). GRAY AREA DALAM PELAKSANAAN PENGAMPUNAN PAJAK. MABIS, 7(2).

Jenkins, J. dan Les Alm. 2003. Movers and Shakers: A Qualitative Questions on The Role of Policy Entrepreneurs. Department Of Public Administration Journal.

Johannes, R. (2016). ANALISIS EFEKTIVITAS IMPLEMENTASI PENGAMPUNAN PAJAK (TAX AMNESTY) DI INDONESIA TAHUN 2016.

Kumalasari, K. I., Wardany, A. R., \& Kumalasari, S. (2017). MENUJU BERAKHIRNYA PROGRAM TAX AMNESTY. Jurnal Penelitian Teori \& Terapan Akuntansi (PETA), 2(1), 65-78. 
RUSTANTI, N. (2017). Hubungan Perilaku dan Kepatuhan Wajib Pajak Terhadap Keberhasilan tax amnesty Tahun 2016.

Moleong, Lexy J. (2007). Metodelogi Penelitian Kualitatif (edisi revisi). Bandung: PT. Remaja Rosdakarya

Winarno, Budi. 2007. Kebijakan Publik-Teori dan Proses. Yogyakarta: MedPress.

\section{Wawancara:}

Hendra Kurniawan (Direktorat Jenderal Pajak bidang Direktorat Penyuluhan, Pelayanan dan Hubungan Masyarakat) Wawancara Tanggal 02 September 2017.

Bhima Yudhistira Adhinegara peneliti (Institute for Development of Economics and Finance (INDEF)Wawancara Tanggal 04 September 2017.

Adi Wirawan (Pihak Metro TV) Wawancara Tanggal 05 September 2017. 